\title{
SNPs and Hox gene mapping in Ciona intestinalis
}

\section{Luigi Caputi*1, Marco Borra², Nikos Andreakis ${ }^{1}$, Elio Biffali ${ }^{2}$ and Paolo Sordino ${ }^{1}$}

\author{
Address: ${ }^{1}$ Department of Biochemistry and Molecular Biology, Stazione Zoologica "A. Dohrn", Napoli, Villa Comunale, Italy and ${ }^{2}$ Molecular \\ Biology Service, Stazione Zoologica "A. Dohrn", Napoli, Villa Comunale, Italy \\ Email: Luigi Caputi* - caputi@szn.it; Marco Borra - borra@szn.it; Nikos Andreakis - nikos.an@szn.it; Elio Biffali - elio@szn.it; \\ Paolo Sordino - sordino@szn.it \\ * Corresponding author
}

Published: 25 January 2008

BMC Genomics 2008, 9:39 doi:10.1 186/147/-2164-9-39
Received: 4 May 2007

Accepted: 25 January 2008

This article is available from: http://www.biomedcentral.com/I47/-2/64/9/39

(C) 2008 Caputi et al; licensee BioMed Central Ltd.

This is an Open Access article distributed under the terms of the Creative Commons Attribution License (http://creativecommons.org/licenses/by/2.0), which permits unrestricted use, distribution, and reproduction in any medium, provided the original work is properly cited.

\begin{abstract}
Background: The tunicate Ciona intestinalis (Enterogona, Ascidiacea), a major model system for evolutionary and developmental genetics of chordates, harbours two cryptic species. To assess the degree of intra- and inter-specific genetic variability, we report the identification and analysis of $C$. intestinalis SNP (Single Nucleotide Polymorphism) markers. A SNP subset was used to determine the genetic distance between Hox-5 and -10 genes.

Results: DNA fragments were amplified from 12 regions of $C$. intestinalis sp. A. In total, 128 SNPs and 32 one bp indels have been identified within $8 \mathrm{~Kb}$ DNA. SNPs in coding regions cause 4 synonymous and 12 non-synonymous substitutions. The highest SNP frequency was detected in the Hox 5 and Hox 10 intragenic regions. In C. intestinalis, these two genes have lost their archetypal topology within the cluster, such that Hox 10 is located between Hox4 and Hox5. A subset of the above primers was used to perform successful amplification in C. intestinalis sp. B. In this cryptic species, 62 SNPs were identified within 3614 bp: 41 in non-coding and 21 in coding regions. The genetic distance of the Hox-5 and -10 loci, computed combining a classical backcross approach with the application of SNP markers, was found to be $8.4 \mathrm{cM}$ (Haldane's function). Based on the physical distance, I cM corresponds to $39.5 \mathrm{~Kb}$. Linkage disequilibrium between the aforementioned loci was calculated in the backcross generation.

Conclusion: SNPs here described allow analysis and comparisons within and between $C$. intestinalis cryptic species. We provide the first reliable computation of genetic distance in this important model chordate. This latter result represents an important platform for future studies on Hox genes showing deviations from the archetypal topology.
\end{abstract}

\section{Background}

A recent phylogeny placed Tunicata as the sister group of vertebrates [1]. This new position rejects traditional views of a Tunicata - Cephalochordata - Vertebrata succession [2-6] and it casts new light on comparative studies [7]. The taxonomic status of $C$. intestinalis $\mathrm{L}$., the tunicate species most widely used for research purposes, was recently resolved with the discovery of two cryptic taxa, named $C$. intestinalis spp. A and B [8-11]. This finding prompts careful re-evaluation of research data, as it is reasonable that literature concerning C. intestinalis sensu Linnaeus refers to both cryptic species. Affinities with vertebrates are visible 
in the body plan organization of ascidian larvae and, despite major morphological rearrangements during metamorphosis, they are also retained in sessile adults $[12,13]$. Sequencing of $C$. intestinalis genome revealed an estimated number of protein-coding genes (15.852 over ca. $160 \mathrm{Mb}$ genome length) similar to invertebrates and only about half of vertebrates [14]. Gene density is estimated to be 1 locus per $7.5 \mathrm{~Kb}$ (compared with $9 \mathrm{~Kb}$ in fruit fly and $100 \mathrm{~Kb}$ in human). C. intestinalis genes contain, on average, 6.8 exons. From the genomic point of view, the presence of several hundred genes having higher sequence similarity with Drosophila melanogaster and Caenorhabditis elegans than with vertebrates [14], as well as the small gene number, are indicative of species ancestry. Moreover, the genome is rich in AT (65\%). Two derived features of the $C$. intestinalis genome are the presence of gene duplication events not detected in vertebrates, and the derived loss of ancestral genes that are conserved in chordates (e.g. paralogy of the Hox groups 7, 8 and 9) [14]. This latter phenomenon has been estimated to be around $35 \%$ and $45 \%$ more frequent in C. intestinalis than, respectively, in pufferfish and humans. Recent data on the congeneric species C. savignyi [15] revealed an impressive level of genomic variation, such that this species exhibits the "... highest rates of [...] polymorphisms ever comprehensively quantified in a multicellular organism". More specifically, C. savignyi shows a very high level of haplome-specific DNA (16.6\%); this degree of variability between single haploid genomes originates from an enormous amount of various size indels throughout the genome [15].

Single nucleotide polymorphisms (SNPs) are one of the most important categories of genetic markers in the field of population genetics and human diseases. SNPs are base pair substitutions in the DNA of individuals [16], and are by far the most common type of molecular polymorphism in living organisms. Given this definition, single base pair insertions/deletions (indels) are not formally considered as SNPs. On the other hand, single base pair substitutions in cDNA are often included in this category of DNA variation, although they may result from errors in mRNA editing. About 1 SNP per Kb and 1 SNP per $125 \mathrm{bp}$ occur in Homo sapiens [17] and Aedes aegypti [18], respectively. This very high variability represents a unique source of molecular markers. Biallelic SNPs are randomly distributed across the genome and have a low mutation rate $\left(10^{-}\right.$ $8-10^{-9}$ ) [19]: this property makes it easier to calculate mutational rates in SNPs than, for example, in microsatellites. Although a restriction to four character states makes SNPs less informative than microsatellites for linkage and population genetics, synonymous coding as well as noncoding SNPs are still useful markers for these applications since they are not under natural selection. Non-synonymous SNPs in coding DNA regions are mostly used to enhance understanding of the molecular genetic basis of phenotypic variation, with a particular relevance for human-disease research. Technical progress in SNP detection [20] has turned this polymorphism into the most reliable marker for genomic approaches. In spite of their importance, few data concerning occurrence of SNPs in natural populations of lower chordates (cephalochordates and tunicates) are available [21]. Such analysis would greatly contribute to a deeper knowledge of genetic variability in evolutionary key model organisms, in particular when research is based on natural populations. In $C$. intestinalis, allelic polymorphism is equal to $1.2 \%$ on average, and it may reach peaks of $10-15 \%$ within short (100 bp) regions [14], although these data are still matter of debate [15]. Large-scale analysis in C. savignyi revealed an average SNP heterozygosity of $4.5 \%$, with a Ts/Tv ratio of 2.45 and a quasi-equal distribution of the various types of transversions [15].

Genes belonging to the Hox family of transcription factors are control leaders in the definition of the antero-posterior axis of all bilaterians analyzed so far. Usually, Hox genes are structured in chromosomal clusters displaying an ordered succession of paralogy group members. A general dogma states the colinearity rule(s): more 3' located genes possess more anterior and earlier onsets of expression (spatial and temporal colinearity, respectively). Recent studies in tunicates $[22,23]$ and in the sea urchin Strongylocentrotus purpuratus [24] revealed that coordinated spatial expression of Hox genes persists even in presence of a rearranged distribution of paralogy groups within the cluster. Therefore, understanding the evolutionary and functional scenarios of unclustered or unconventionally clustered Hox genes is a crucial task.

Herein, we studied SNP occurrence in C. intestinalis sp. A and sp. B. We developed exon-primed-intron-centered (EPIC) [25] primers in order to allow inter-specific genetic comparisons in 2 coding and 10 non-coding regions. For two adjacent Hox genes (Hox-10 and -5) displaying an inverted position, genetic distance and linkage disequilibrium (LD) were calculated using SNP markers in a backcross panel.

\section{Results and discussion DNA amplification and detection of SNPs}

A total of 16 EPIC and 2 non-EPIC primer pairs were PCRtested on 30 genomic DNA samples from different $C$. intestinalis sp. A populations. Twelve primers were used to amplify reliable products (Fig. 1), ranging from 357 to 1340 bp length (Table 1). Consequently, we analyzed a total of 7966 bp: 5953 from intronic nuclear regions, 1498 from two nuclear exons (Hox13 and Gsx) and 515 from the mt-DNA COI (cytochrome oxydase subunit I) gene. We detected 128 transition/transversion SNPs (110 

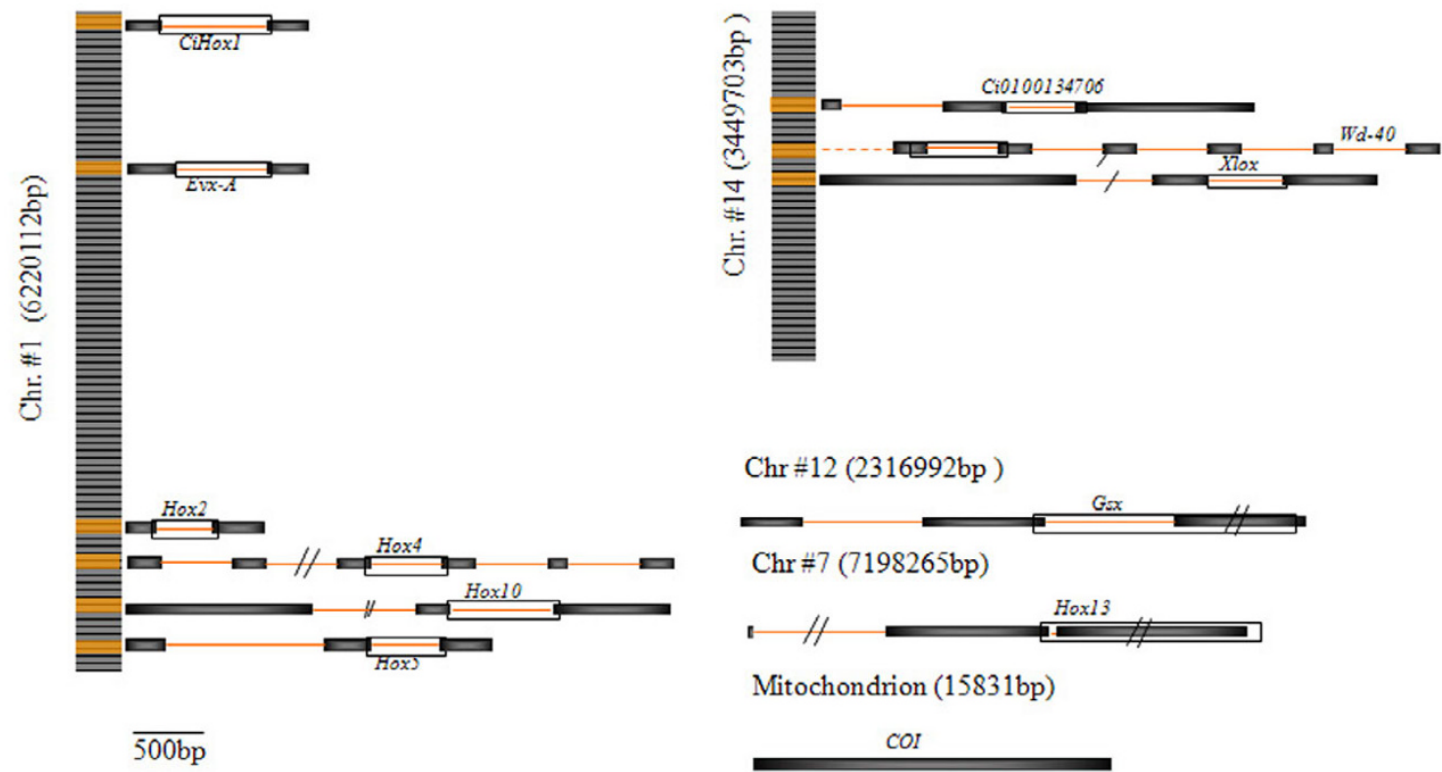

\section{Figure I}

Structure and location of loci. Exon-intron structure and genomic location of genic loci used for analyses. Empty boxes: amplified regions. Chromosomes are numbered according to [28]. Distances between genes are indicative. All data are inferred from $C$. intestinalis sp. A.

in non-coding regions) and 32 single base indels (29 in non-coding regions).

No SNPs were observed in the mitochondrial COI gene, 3 in the Hox13 and 15 in the Gsx coding regions. Our data indicate that the observed transition/transversion $\left(\mathrm{T}_{\mathrm{s}} / \mathrm{T}_{\mathrm{v}}\right)$ ratio in the coding regions analyzed in this study is equal to 5.0 (Table 1 ). The $\mathrm{T}_{\mathrm{s}} / \mathrm{T}_{\mathrm{v}}(1.37)$ observed within $C$. intestinalis sp. A coding and non-coding regions is considerably lower than the ratio found in C. savignyi (2.45) [15]. This difference is likely due to the regions here analyzed, namely non-coding intragenic and coding genic, whereas previous estimations were based on all genome sequences $[15,16,26,27]$.

SNP frequency distribution in the non-coding DNA amplified regions displays a high degree of variability. Hox-1, -2, -10, -5 and EvxA genes are sequentially located along the chromosome \#1 [23,28]. Notably, the highest SNP frequency occurs within those Hox genes (Hox-5 and -10) that have lost the archetypal genomic organization.

\section{Types and frequencies of SNPs}

Overall, SNPs represent $48 \%$ of sequence polymorphisms in the $8 \mathrm{~Kb}$ region analyzed in this study, with a frequency of 1.61 SNPs every 100 bp (Table 1). The remaining 52\% of polymorphisms consists of 1 bp or longer indels and multiple nucleotide polymorphisms. The high level of
non-SNPs fits well with previous estimates in other multicellular organisms [15].

The occurrence of SNPs partially reflects the different $C$. intestinalis populations. For instance, all nine individuals from the Fusaro Lagoon display a $\mathrm{T} \leftrightarrow \mathrm{C}$ transition at position 114 of the Hox5 locus, while only two individuals present an $A \leftrightarrow G$ transition at position 111. In particular, most of non-synonymous changes are carried by individuals from geographically disjunct populations (e.g. California, Japan and Italy). Strain-specificity of nonsynonymous SNPs is generally assumed to reflect adaptive responses to distinct environmental conditions [29-31].

Concerning non-coding DNA regions, the overall number $\left(\Sigma_{\mathrm{Ts}}=59 ; \Sigma_{\mathrm{Tv}}=51-\right.$ Table 1$)$ and frequency $\left(\mathrm{f}_{\mathrm{Ts}}=0.01 ; \mathrm{f}_{\mathrm{Tv}}\right.$ $=0.008-$ Table 1 and Fig. 2) of transition SNPs is slightly predominant. Furthermore, analysis of nuclear exonic regions indicates that the aforementioned transition prevalence is even more evident in the coding DNA ( $83 \%$ of total SNPs). This is not surprising since it is generally accepted that the frequently occurring 5-methylcytosine de-amination reactions cause transition overrepresentation in genomes [32]. Significant differences in the $T_{s} / T_{v}$ ratio between non-coding and coding DNA regions have been previously observed [27], indicating that transitions occur more frequently in coding regions. Polymorphisms along the $1.5 \mathrm{~Kb}$ nuclear coding DNA causes 4 synony- 
Table I: Nucleotide polymorphisms in C. intestinalis sp. A loci.

\begin{tabular}{|c|c|c|c|c|c|c|c|c|c|c|c|c|c|c|c|c|c|c|c|c|c|c|}
\hline Gene & bp & $\mathrm{nH}$ & Ts & & & & $\mathbf{T r}$ & & & & & & Ts/Tv & $\sum_{\mathbf{S N P s}(t s+t v)}$ & I bp indel & $\sum_{\mathbf{P S}}$ & $\sum_{\mathbf{S N P S}} I_{\mathbf{P S}}$ & $\pi$ & $\mathbf{f}_{\mathrm{SNPs}}$ & $\mathbf{f}_{\Sigma \mathbf{P S}}$ & T93 & L'sP \\
\hline & & & AG & CT & $\Sigma_{\mathbf{T s}}$ & $\%$ & AC & AT & GC & GT & $\Sigma_{\mathbf{T v}}$ & $\%$ & & & & & & & & & & \\
\hline HoxI & 573 & 4 & 1 & 3 & 4 & 40 & 2 & 3 & 1 & 0 & 6 & 60 & 0.67 & 10 & 4 & 16 & 0.62 & 0.017 & 0.020 & 0.03 & 0.007 & 0.012 \\
\hline Hox2 & 531 & 3 & I & 0 & I & 50 & 0 & I & 0 & 0 & I & 50 & 0.5 & 2 & I & 3 & 0.67 & 0.002 & 0.004 & 0.005 & 0.000002 & 0.000066 \\
\hline Hox4 & 357 & 3 & 0 & 0 & 0 & 0 & 0 & I & 0 & 0 & I & 100 & 0 & 1 & I & 2 & I & 0.002 & 0.006 & 0.006 & 0.0028 & 0.0062 \\
\hline Hox5 & 481 & 11 & 10 & 8 & 18 & 72 & 1 & 6 & 0 & 0 & 7 & 28 & 2.57 & 25 & 3 & 45 & 0.55 & 0.024 & 0.052 & 0.093 & 0.004 & 0.004 \\
\hline Hox 10 & 531 & 8 & 10 & 5 & 15 & 43 & I & 15 & 0 & 4 & 20 & 57 & 0.75 & 35 & 8 & 61 & 0.57 & 0.038 & 0.066 & 0.115 & 0.004 & 0.003 \\
\hline EvxA & 569 & 3 & 0 & 0 & 0 & 0 & 0 & 2 & 0 & 0 & 2 & 100 & 0 & 2 & I & 3 & 0.67 & 0.002 & 0.003 & 0.005 & 0.0035 & 0.0039 \\
\hline Xlox & 707 & 5 & 3 & 2 & 5 & 55 & 0 & I & 3 & 0 & 4 & 45 & 1.25 & 9 & I & 16 & 0.56 & 0.006 & 0.013 & 0.022 & 0.000002 & 0.0018 \\
\hline Gsx & 186 & 6 & I & I & 2 & 100 & 0 & 0 & 0 & 0 & 0 & 0 & 0 & 2 & 0 & 15 & 0.13 & 0.012 & 0.01 & 0.08 & 0.0035 & 0.003706 \\
\hline Wd-40 & 1340 & 4 & 2 & 0 & 2 & 28 & 3 & I & 0 & 1 & 5 & 72 & 0.4 & 7 & 3 & 30 & 0.23 & 0.008 & 0.005 & 0.028 & 0.0084 & 0.231 \\
\hline \multirow[t]{2}{*}{ ci0100134706 } & 678 & 4 & 6 & 6 & 12 & 70 & 0 & 2 & 0 & 3 & 5 & 30 & 2.4 & 17 & 7 & 38 & 0.45 & 0.019 & 0.025 & 0.056 & 0.03 & 0.04 \\
\hline & 5953 & & 34 & 25 & 59 & 54 & 7 & 32 & 4 & 8 & 51 & 46 & 1.18 & 110 & 29 & 229 & 0.48 & & 0.019 & 0.038 & & \\
\hline Gsx & 897 & 4 & 5 & 8 & 13 & 87 & 0 & 2 & 0 & 0 & 2 & 13 & 6.5 & 15 & 0 & 15 & 1 & 0.011 & 0.017 & 0.017 & 0.00452 & 0.004575 \\
\hline Hox 13 & 601 & 2 & I & I & 2 & 67 & 0 & 0 & 0 & I & 1 & 33 & 2 & 3 & 3 & 11 & 0.27 & 0.008 & 0.005 & 0.025 & 0.01188 & 0.016926 \\
\hline \multirow[t]{2}{*}{$\mathrm{COI}$} & 515 & 1 & 0 & 0 & 0 & 0 & 0 & 0 & 0 & 0 & 0 & 0 & 0 & 0 & 0 & 0 & 0 & 0 & 0 & 0 & 0 & 0 \\
\hline & 2013 & & 6 & 9 & 15 & 83 & 0 & 2 & 0 & I & 3 & 17 & 5.0 & 18 & 3 & 26 & 0.69 & & 0.009 & 0.013 & & \\
\hline
\end{tabular}

Abbreviations: bp, length of the amplified sequence; $\mathrm{nH}$, number of haplotypes; Ts, transition; Tv, transversion; $\sum$, total; PS, polymorphic sites; $\pi$, nucleotide diversity; f, frequency; T93, TamuraNei genetic distance (1993); L'sP, Lake's paralinear genetic distance. 


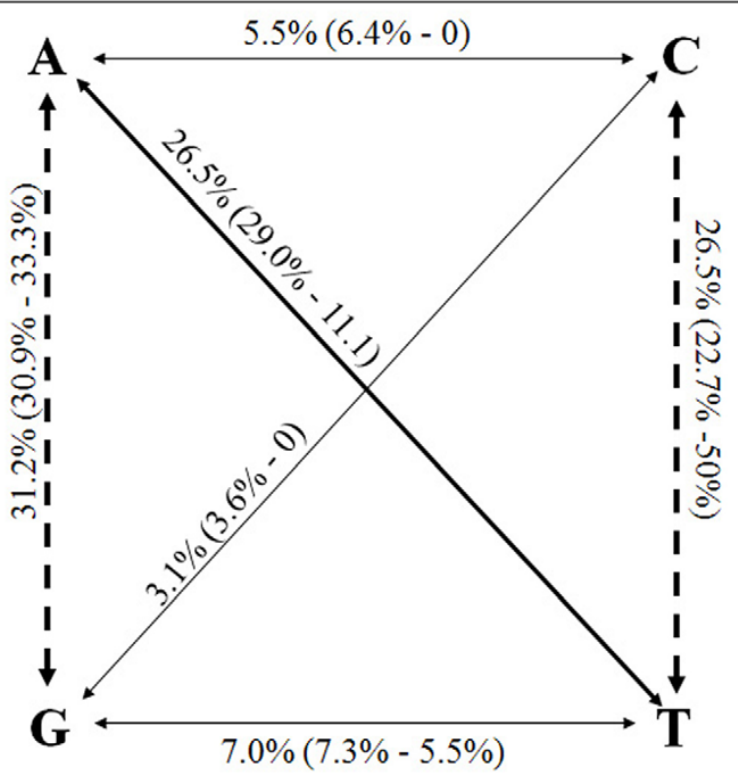

Figure 2

SNPs in Ciona intestinalis sp. A. Percentage of transversion and transition SNPs in C. intestinalis sp. A. Values outside parenthesis indicate the total percentage of each substitution type calculated over all DNA polymorphisms. Values within parenthesis indicate the percentage of each substitution type calculated, respectively, over non-coding and coding regions.

mous and 12 non-synonymous changes (Table 2). The synonymous/non-synonymous $(\mathrm{S} / \mathrm{nS})$ ratio $(0.333)$ here reported is in contrast with the average $\mathrm{S} / \mathrm{nS}$ ratio found in C. savignyi (5.16) [15]. It is assumed that overrepresentation of non-synonymous nucleotide changes is strictly associated with adaptive evolution [33,34]. In agreement, this mechanism may have played a crucial role in functional divergence of Hox genes after cluster duplications along the vertebrate lineage [35]. Being tunicates the closest relatives of vertebrates, our data lend support to the hypothesis that adaptive evolution on Hox and ParaHox genes was already active in basal chordates.

Table 2: C. intestinalis spp. A \& B synonymous and nonsynonymous substitutions.

\begin{tabular}{lllll}
\hline Gene & sp & S & nS & S/nS \\
\hline Gsx & A & I & 8 & 0.12 \\
Hox 13 & A & 3 & 4 & 0.75 \\
COI & A & 0 & 0 & - \\
Hox 13 & B & I & 6 & 0.16 \\
COI & B & 2 & 5 & 0.40 \\
\hline
\end{tabular}

Abbreviations: sp, cryptic species; S, synonymous substitutions; $\mathrm{nS}$, non-synonymous substitutions.
Among different genes herein analyzed, non-coding DNA SNPs are highly variable in types and frequency. Transitions are predominant in 4/10 loci, while transversions prevail in 5/10. In one case (Hox 2$), \mathrm{T}_{\mathrm{s}} / \mathrm{T}_{\mathrm{v}}$ ratio is equal to one. The two transition substitution types are comparably represented (57.6\% A $\leftrightarrow \mathrm{G}, 42.3 \% \mathrm{~T} \leftrightarrow \mathrm{C}$ ). Concerning transversions, $\mathrm{A} \leftrightarrow \mathrm{T}$ substitutions are prevalent (70.6\%), while $\mathrm{A} \leftrightarrow \mathrm{C}, \mathrm{G} \leftrightarrow \mathrm{C}$ and $\mathrm{G} \leftrightarrow \mathrm{T}$ are underrepresented (13.7\%, 7.8\%, 15.7\%, respectively). However, $46.9 \%$ of all $\mathrm{A} \leftrightarrow \mathrm{T}$ transversions are from a single intron (Hox10) and all four types of transversions are never observed at a single locus.

Twenty-nine 1 base-pair indels were found in the analyzed non-coding loci, and 3 in the Hox 13 coding region. All indels in coding DNA were found in only one individual from an Adriatic sea population. Whether this data reflects partial or total loss of function of Hox13 remains elusive. Unlike coding sequences, all analyzed non-coding regions present a clear quantitative relationship between SNPs and 1 bp indels (Fig. 3), in support of some kind of structural and/or functional correlation between mechanisms leading to the appearance of different types of polymorphism [14].

\section{SNPs in Ciona intestinalis sp. B}

All pairs of EPIC primers used to amplify C. intestinalis sp. A genomic DNA were successfully tested in $C$. intestinalis sp. B (Table 3). Among them, 5 associated with non-coding (Hox-1, -2, -5, -10 and Xlox - 2503 bp) and 2 with coding regions (Hox13 and COI - $1111 \mathrm{bp}$ ) have been used to investigate SNP presence, using 5 to 10 specimens for each

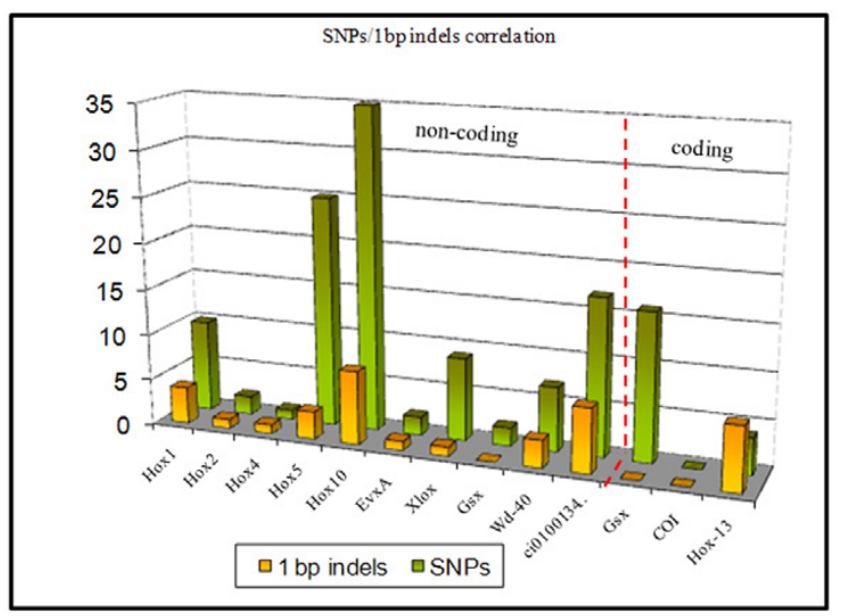

Figure 3

Correlation between SNPs and I bp Indels distribution. Quantitative relationships between SNPs and I bp indels in 13 genic loci of $C$. intestinalis sp. A. Except for Gsx and $\mathrm{Hox} / 3$ coding sequences, the two types of polymorphism appear to be tightly correlated. 
Table 3: Nucleotide polymorphisms in C. intestinalis sp. B loci.

\begin{tabular}{|c|c|c|c|c|c|c|c|c|c|c|c|c|c|c|c|c|c|c|c|c|c|c|}
\hline Gene & bp & $\mathrm{nH}$ & Ts & & & & Tv & & & & & & Ts/Tv & $\sum_{\text {SNPs (tsttv) }}$ & I bp indel & $\sum_{\mathbf{P S}}$ & $\sum_{\text {SNPS }} I_{\text {PS }}$ & $\pi$ & $\mathbf{f}_{\text {SNPs }}$ & $\mathbf{f}_{\Sigma \mathrm{PS}}$ & T93 & L'sP \\
\hline & & & AG & CT & $\Sigma_{\text {Ts }}$ & $\%$ & AC & AT & GC & GT & $\Sigma_{\mathbf{T V}}$ & $\%$ & & & & & & & & & & \\
\hline Hoxl & 349 & 2 & 0 & 1 & 1 & 100 & 0 & 0 & 0 & 0 & 0 & 0 & - & 1 & 0 & 1 & - & 0.002 & 0.003 & 0.003 & 0.0028 & 0.0028 \\
\hline Hox2 & 530 & 5 & 3 & 3 & 6 & 75 & 0 & I & 0 & 1 & 2 & 25 & 3 & 8 & 7 & 24 & 0.3 & 0.008 & 0.015 & 0.045 & 0.0019 & 0.0021 \\
\hline Hox5 & 383 & 5 & 4 & 2 & 6 & 37 & 4 & 3 & 0 & 3 & 10 & 63 & 0.6 & 16 & I & 27 & 0.4 & 0.028 & 0.042 & 0.07 & 0.0267 & 0.0268 \\
\hline Hox 10 & 537 & 2 & 5 & 0 & 5 & 83 & 0 & I & 0 & 0 & 1 & 17 & 5 & 6 & 9 & 17 & 0.3 & 0.011 & 0.011 & 0.032 & 0.0116 & 0.0207 \\
\hline \multirow[t]{2}{*}{ Xlox } & 704 & 9 & 4 & 3 & 7 & 70 & 0 & I & 2 & 0 & 3 & 30 & 2.3 & 10 & 11 & 35 & 0.3 & 0.006 & 0.014 & 0.05 & 0.000002 & 0.0017 \\
\hline & 2503 & 23 & 16 & 9 & 25 & 61 & 4 & 6 & 2 & 4 & 16 & 39 & 1.6 & 41 & 28 & 104 & 0.4 & & 0.016 & 0.04 & & \\
\hline $\mathrm{COI}$ & 515 & 5 & 5 & 5 & 10 & 100 & 0 & 0 & 0 & 0 & 0 & 0 & - & 10 & I & 12 & 0.8 & 0.009 & 0.019 & 0.025 & 0.0039 & 0.0048 \\
\hline Hox 13 & 596 & 5 & 6 & 3 & 9 & 82 & 0 & I & 0 & 1 & 2 & 18 & 4.05 & 11 & 1 & 23 & 0.5 & 0.016 & 0.018 & 0.038 & 0.0067 & 0.0099 \\
\hline Tot & IIII & & II & 8 & 19 & 90 & 0 & I & 0 & I & 2 & 10 & 9.5 & 21 & 2 & 35 & 0.6 & & 0.019 & 0.031 & & \\
\hline
\end{tabular}

Abbreviations: bp. length of the amplified sequence; $\mathrm{nH}$. number of haplotypes; Ts. transition; Tv. transversion; $\Sigma$. total; PS. polymorphic sites; $\pi$. nucleotide diversity; f. frequency; T93. Tamura-Nei genetic distance (1993); L'sP. Lake's paralinear genetic distance. 
locus. In total, 62 SNPs were detected (41 in non-coding, 21 in coding regions). On average, 1.89 SNPs were detected every $100 \mathrm{bp}$ in coding regions, compared with 0.27 SNPs every $100 \mathrm{bp}$ in the same C. intestinalis sp. A loci. In the cryptic species $\mathrm{B}, \operatorname{Hox} 13$ SNP frequency is higher than the one detected in non-coding regions ( $\mathrm{f}=$ 0.018 vs 0.016 ). SNPs cause 1 synonymous and 6 nonsynonymous amino acidic changes at the Hox13 locus, and 2 synonymous and 5 non-synonymous at the COI locus (Table 2). Previous analysis indicated the presence of a single mitochondrial haplotype shared by all Mediterranean populations of $C$. intestinalis sp. A. Conversely, $C$. intestinalis sp. B displays a variable COI in north European seas, suggestive of fixed populations [8]. Present results support the idea that the actual status of $C$. intestinalis $\mathrm{sp}$. A in the Mediterranean Sea is due to a colonization by a mitochondrial variant, as well as the existence of more structured C. intestinalis sp. B populations [8].

Among SNPs in non-coding regions, the $\mathrm{T}_{\mathrm{s}} / \mathrm{T}_{\mathrm{v}}$ ratio is equal to 1.56 , and so it is similar to the ratio detected in sp. A (1.18). A $\leftrightarrow \mathrm{G}$ are more frequent than $\mathrm{C} \leftrightarrow \mathrm{T}$. A $\leftrightarrow \mathrm{T}$ are the most common transversion. The ratio of SNP mutations over total polymorphisms $\left(\sum_{\mathrm{SNPS}} / \sum_{\mathrm{PS}}\right)$ is similar in the two cryptic species $\left[\sum_{\mathrm{SNPs}} / \sum_{\mathrm{PS}}=0.48\right.$ (sp. A) and $\Sigma_{\mathrm{SNPS}} / \Sigma_{\mathrm{PS}}=0.39$ (sp. B)].

In conclusion, all EPIC and non-EPIC primers that were designed taking advantage of the genome sequence of $C$. intestinalis sp. A, perfectly amplify homologous loci in $C$. intestinalis sp. B. Opposite to coding regions, frequency and $\mathrm{T}_{\mathrm{s}} / \mathrm{T}_{\mathrm{v}}$ ratio in non-coding regions are very similar. Altogether, data are suggestive of genome behavior in the two cryptic species with shared and divergent traits.

\section{Genomic location}

The organization of the Hox cluster in C. intestinalis [23] is characterized by an atypical arrangement. Two main differences can be observed: a) the cluster is broken (Hox-12 and -13 are located on a different chromosome) and b) paralogy groups do not respect the canonical 3' $\rightarrow$ 5' succession (Hox-4 and -5 are separated by Hox10) (Fig. 1). In this context, variability at these loci acquires a peculiar relevance. Our analysis shows (Table 1) that, among all analyzed loci (and among the same subset of specimens), Hox 5 and Hox10 display the highest nucleotide diversity $\left(\pi_{\text {Hox } 5}=0.0241 ; \pi_{H o x 10}=0.038\right)$ in non-coding regions. Similarly, the total number $\left(\sum_{H o x 5}=25 ; \sum_{H o x 10}=35\right)$ and frequency $\left(\mathrm{f}_{\text {Hox } 5}=0.052 ; \mathrm{f}_{\text {Hox } 10}=0.066\right)$ of SNPs are the highest ones. In these loci, the number of observed transition substitutions is the highest among all genes analyzed, while the number of $\mathrm{A} \leftrightarrow \mathrm{T}$ transversions is notably overrepresented in the Hox10 non-coding region (15 vs 3.4 on average). Tamura and Nei (TN93) and Lake's Paralinear (L'sP) genetic distance calculated within the same sub- sample of specimens, concordantly assign higher values (TN93 $_{\text {Hox } 5}=0.004 ;$ TN93 $_{\text {Hox } 10}=0.004 ;$ L'sP $_{\text {Hox } 5}=0.004$; $\mathrm{L}^{\prime} \mathrm{SP}_{\text {Hox10 }}=0.003$ ) to Hox5 and Hox10 than to any other loci screened for SNPs (Table 1).

The Hox2 and Hox4 genes have retained the archetypal genomic topology within the genome of $C$. intestinalis sp. A. These loci display a low SNP frequency $\left(\sum_{H o x-2,-4}=3\right.$; $\left.\mathrm{f}_{H o x-2,-4}=0.0034\right)$. More generally, the total number of polymorphisms (including indels and multiple base polymorphisms $\left.-\sum_{\mathrm{PS}}=5\right)$ and nucleotide diversity $\left(\sum_{\text {Hox-2,Hox- }}\right.$ ${ }_{4}=0.0022$ ) is notably low.

\section{Haplotypes structure, linkage disequilibrium and genetic mapping}

With the aim to genetically characterize populations of $C$. intestinalis sp. A inhabiting the Fusaro lagoon (FuI) and the harbour of Castellamare di Stabia (CdS) (Tyrrhenian Sea, Italy), we have identified 11 distinct haplotypes for the Hox5 locus, and 7 for the Hox10 one (Fig. 4). Specimens carrying the most frequent haplotypes (named F5-2, C5-1, F10-1, C10-3) have been selected as parental individuals in a backcross for SNP-based LD and genetic mapping of this region. In four (3.4\%) of 120 backcross individuals, analysis failed to detect any SNPs in both loci. In addition, detection of Hox 5 and Hox10 SNPs failed in, respectively, $6(5.0 \%)$ and $4(3.4 \%)$ individuals. The final matrix consisted of 116 samples, using a 50\% threshold for missing genotypes. Observed $v$ s expected heterozygosity was calculated with Haploview using phased haplotype files. We evaluated LD in the backcross generation using the Lewontin's D' [36] and correlation factor $r^{2}$ [37].

Linkage disequilibrium [D'] between genic loci is equal to 0.92 , and $\mathrm{r}^{2}$ is 0.74 (Fig. 5). The coefficient $\mathrm{r}^{2}$ increases in the backcross generation from the value detected in $\mathrm{F}_{0}$ (0.67). A genetic map was generated anchoring SNP loci to the same chromosome with MapMaker/exp v.3. The obtained cM value (according to Haldane's function) is 8.4 , with a 28.59 threshold between the two loci. Linkage was correlated with physical distances by using a genome browser (C. intestinalis v2.0, Joint Genome Institute) [14]. Being Hox10 and Hox5 separated by $331799 \mathrm{~Kb}$, including some unresolved nucleotide stretches (N), 1 cM corresponds to $39.5 \mathrm{~Kb}$ (Fig. 6).

The recombination ratio for the Hox10/Hox5 region in $C$. intestinalis sp. A is consistent with previous results, despite some ambiguity concerning the taxonomic status of parents [38]. In the highly polymorphic $\mathrm{Fu} / \mathrm{Hc}$ locus of the colonial tunicate, Botryllus schlosseri, $1 \mathrm{cM}$ corresponds to approximately $90 \mathrm{~Kb}$ [39]. Hence, the high recombination rate of the Hox10/Hox5 region is suggestive of a peculiar variability, and it provides an interesting point of discussion about disrupted topology of Hox clusters. 

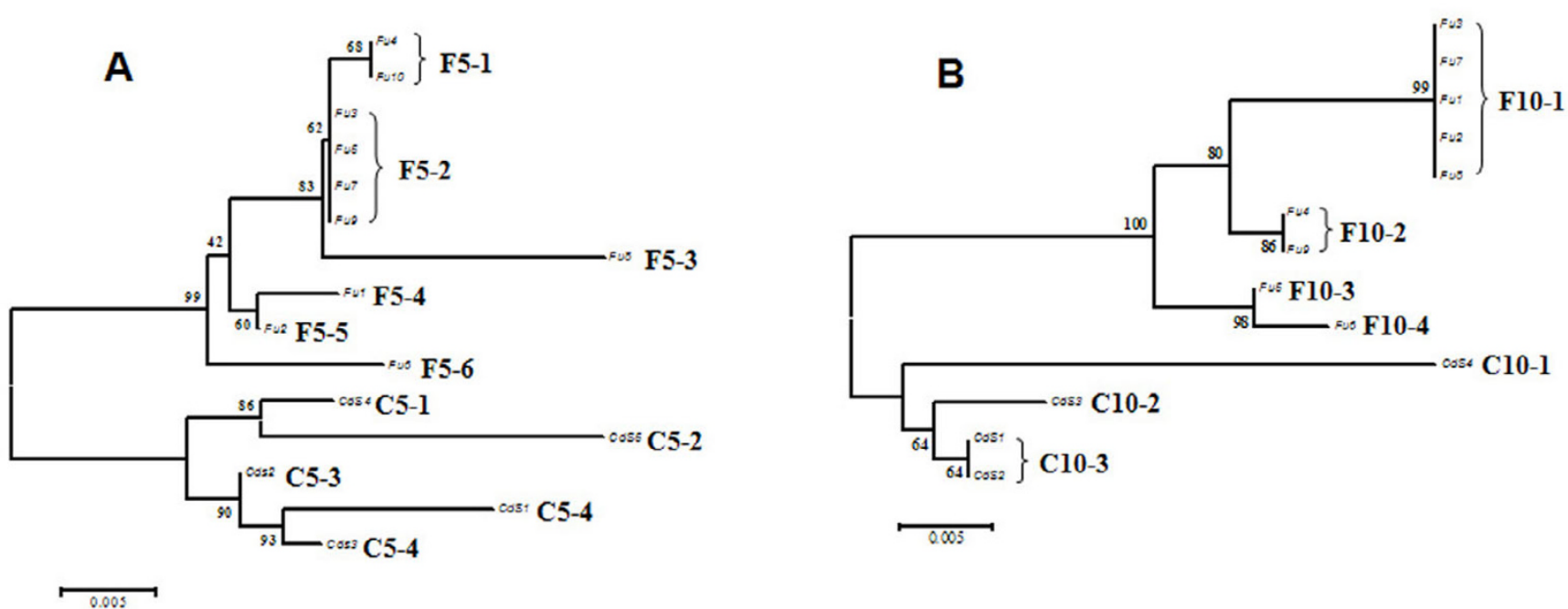

Figure 4

Hox5 and Hox 10 haplotypes. Maximum Parsimony trees of Hox5 (A) and Hox 10 (B) haplotypes in Fusaro (F) and Castellamare di Stabia (C) populations. Individuals carrying the most common haplotypes (F5-I/C5-I and FI0-I/CI0-3) were used as parents to generate the backcross progeny.

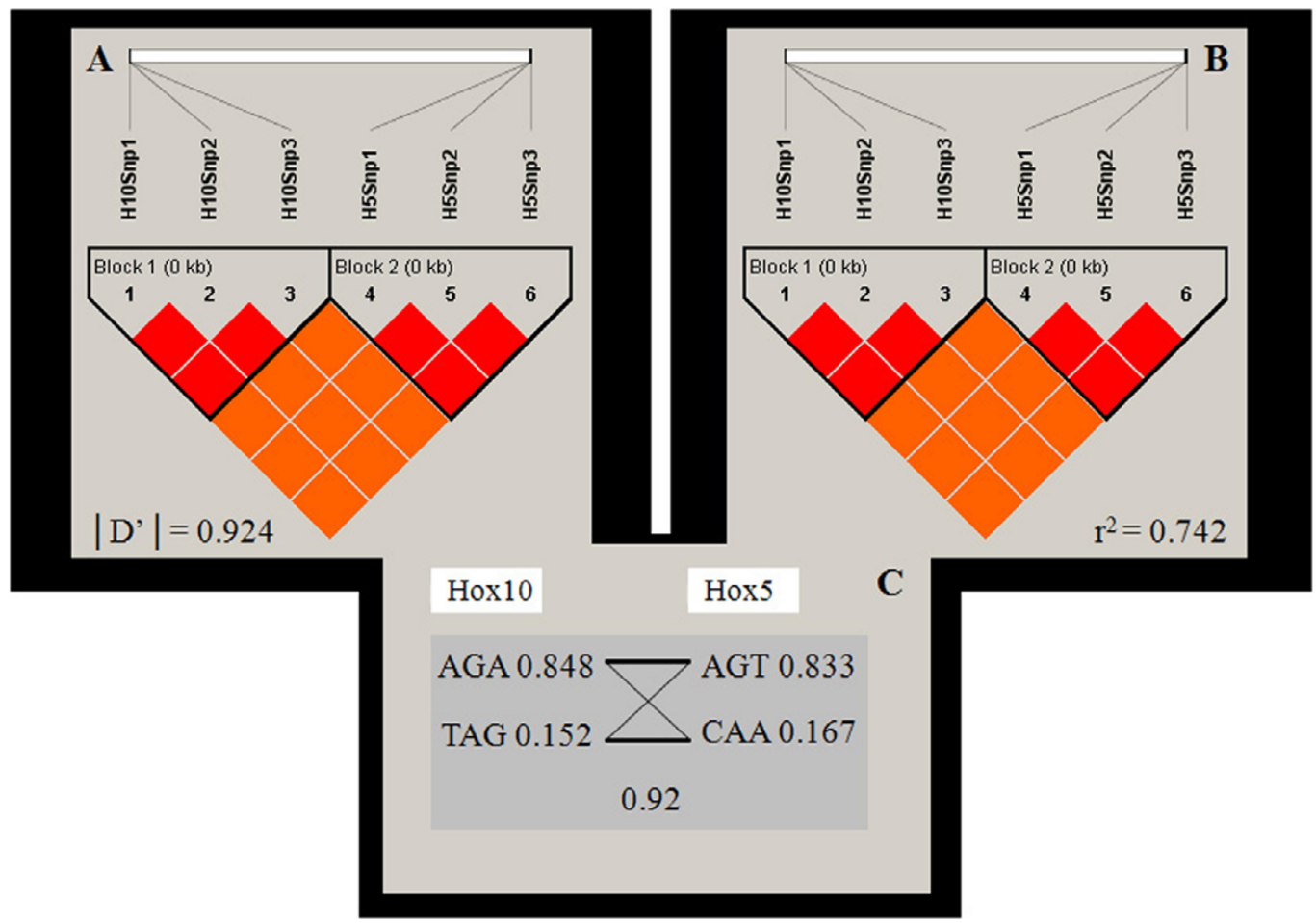

\section{Figure 5}

Linkage disequilbrium. Linkage disequilibrium |D'| (A) and $\mathrm{r}^{2}(\mathrm{~B})$ calculated between Hox5 and Hox 10 loci using three SNP markers per locus. Values are only referred to orange blocks. (C) Haplotypes and their population frequency. Letter blocks correspond to the six SNP types. Thin lines connect haplotypes with a frequency $>0.1 \%$; thick lines connect haplotypes with a frequency $>10.0 \%$. The recombination $D^{\prime}$ value between the two blocks is shown. 


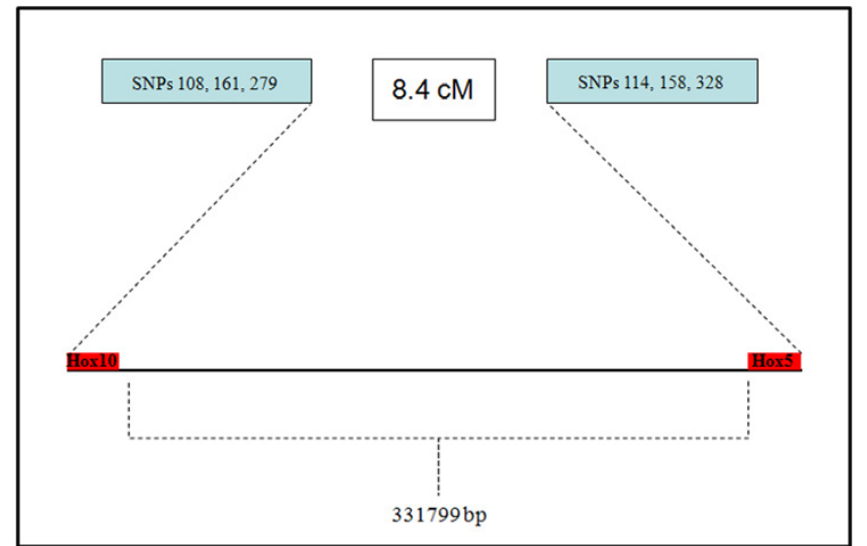

Figure 6

Genetic and physical map. Genetic and physical distances between Hox 10 and Hox 5 loci computed using 3 SNP markers per gene in the backcross generation. Numbers following SNPs indicate the substitution position within the sequence. Physical distance was inferred from the JGI C. intestinalis v.2.0 genome sequence.

\section{SNP reliability}

Different methods were used in order to assess the validity of the SNPs analyzed in the present paper. First, only SNPs confirmed by two independent PCR, three clones for each PCR, were kept for further analysis. This first step was applied in both C. intestinalis sp. A and sp. B. Second, we analyzed segregation ratios in the FuI/CdS $\mathrm{F}_{1}$ crosses. All SNPs displayed the expected 1:1 ratio of Mendelian inheritance. Therefore, all data herein reported are reliably not due to sequencing artifacts.

\section{Conclusion}

We identified 128 SNPs through sequencing of $8 \mathrm{~Kb}$ genomic DNA of C. intestinalis sp. A. All primers used to amplify genomic DNA were successfully tested in C. intestinalis sp. B, allowing inter-specific comparison. As expected, SNP frequency is lower in coding than in noncoding regions $[40,41]$. Also, SNP frequency is not constant in intronic DNA. Variability likely depends on the genomic location of analyzed sequence. In particular, we identified a highly polymorphic region in correspondence of Hox5 and Hox10, two genes that have inverted their paralogy group position within the typical topology of Hox clusters. The dominance of non-synonymous vs synonymous SNPs in Hox coding regions suggests that adaptive evolution is acting on these genes. In order to establish the genetic map of this region, we performed a SNP-based approach to measure $\mathrm{cM}$ distance between two Hox genes in a backcross generation. We calculated linkage disequilibrium and correlated genetic and physical distances.
In this report, we analyzed SNP occurrence in C. intestinalis sp. A at intra- and inter-population levels, providing an important source of genetic markers for linkage, population and comparative studies. Our data indeed represent a further step toward the establishment of a unique integrative system for comparative genomics in chordates, consisting of two cryptic (C. intestinalis sp. A \& B) and one congeneric (C. savignyi) species.

We also calculated the genetic distance within a genomic region of particular interest. This data will contribute to in-depth investigations concerning the mechanisms the maintain Hox colinearity in absence of a coordinated genomic organization.

\section{Methods Collection of Ciona intestinalis sp. A and B specimens} Individuals of Ciona intestinalis sp. A were collected in the following localities: Fusaro Lagoon (Italy), Castellamare di Stabia (Italy), Villaggio Coppola (Italy), Taranto (Italy), Venice (Italy), Lake Timsah (Egypt) and Alicante (Spain). Californian and Japanese sequences were obtained from the JGI Ciona intestinalis v2.0 genome [42] and the Ghost Database [43].

Ciona intestinalis sp. B specimens were obtained from the following localities: Plymouth Sound and Edinburgh (United Kingdom), Brest (France), Breskens Harbour (The Netherlands) and Fiskebäckskil (Sweden).

\section{DNA amplification and sequencing}

Genomic DNA was extracted as previously described [8]. Amplification of DNA fragments was performed as in [8], except for the following loci: Hox-1, -2, -10, EvxA, Xlox, Wd-40 and ci0100134706 (see Table 4 for details). PCR products were extracted and purified using the QIAquick Gel Extraction Kit (Qiagen), and then cloned into TOPO TA Cloning Vector (Invitrogen) following manufacturer's instruction. Two independent PCR and three clones for each gene were sequenced using the Applied Biosystems 3730 DNA Analyzer Apparatus at the Molecular Biology Service (SBM) of the Stazione Zoologica "A. Dohrn" in Naples. Sequences were automatically aligned using ClustalW [44] and hand-checked with Bioedit v. 7.0.5.3 [45].

\section{SNP discovery and analysis}

SNPs were identified as sequence differences in the alignment. Only SNPs detected in all different trials were considered valid. All analyses were performed using DAMBE v.4.5.33 [46] and DnaSP v.4.0 [47]. Maximum Parsimony trees were inferred using MEGA v.3.1 [48] with 1000 bootstrap replications. To facilitate detection of SNPs for backcross genotyping, we have chosen 3 SNPs for each of the two Hox genes. Marker selection was done considering a) distance between SNPs (primer design), b) charac- 
Table 4: Markers, primers and thermal cycle conditions.

\begin{tabular}{|c|c|c|c|}
\hline Marker & Forward oligo (5' to $\left.3^{\prime}\right)$ & Reverse oligo (5' to $3^{\prime}$ ) & Cycle conditions \\
\hline HoxI & GCATTGGGCCTTAATGAAACCC & СTTCTGCTTCATACGTCGAT & $95^{\circ} \mathrm{C}\left(3^{\prime}\right) \cdot\left[94\left(30^{\prime \prime}\right) \cdot 56^{\circ} \mathrm{C} \cdot\left(30^{\prime \prime}\right) \cdot 72^{\circ} \mathrm{C}\left(\mathrm{I}^{\prime}\right)\right] \times 34.72^{\circ} \mathrm{C} \cdot\left(3^{\prime}\right)$ \\
\hline Hox2 & CGGACTGCTTACACCAACACC & TCGGCGCTTGTTACGTCACA & $95^{\circ} \mathrm{C}\left(3^{\prime}\right) .\left[94\left(30^{\prime \prime}\right) \cdot 55^{\circ} \mathrm{C} \cdot\left(30^{\prime \prime}\right) .72^{\circ} \mathrm{C}\left(\mathrm{I}^{\prime}\right)\right] \times 30.72^{\circ} \mathrm{C} .\left(3^{\prime}\right)$ \\
\hline Hox 4 & ACGCGACACCAGGTACTTGAA & ATATGCACGGCCGTGGGAAA & $95^{\circ} \mathrm{C}\left(3^{\prime}\right) \cdot\left[94\left(30^{\prime \prime}\right) \cdot 57^{\circ} \mathrm{C} \cdot\left(30^{\prime \prime}\right) \cdot 72^{\circ} \mathrm{C}\left(\mathrm{I}^{\prime}\right)\right] \times 30 \cdot 72^{\circ} \mathrm{C} \cdot\left(3^{\prime}\right)$ \\
\hline Hox 10 & GCAAGAAACGAGTGCCGTACA & CTTCACTTGACGGTCGGTAAG & $95^{\circ} \mathrm{C}\left(3^{\prime}\right) \cdot\left[94\left(30^{\prime \prime}\right) \cdot 57^{\circ} \mathrm{C} \cdot\left(30^{\prime \prime}\right) \cdot 72^{\circ} \mathrm{C}\left(\mathrm{I}^{\prime}\right)\right] \times 30.72^{\circ} \mathrm{C} \cdot\left(3^{\prime}\right)$ \\
\hline Wd-40 & TAGCTCGAGTTTGGGATATG & TGGGTTAAGAGGGTGAGTGG & $\begin{array}{l}95^{\circ} \mathrm{C}\left(5^{\prime}\right) .\left[94\left(I^{\prime}\right) .54^{\circ} \mathrm{C} .\left(2^{\prime}\right) .72^{\circ} \mathrm{C}\left(3^{\prime}\right)\right] \times 35.72^{\circ} \mathrm{C} .\left(10^{\prime}\right) . \\
72^{\circ} \mathrm{C} .\left(3^{\prime}\right)\end{array}$ \\
\hline $0100134706 \mathrm{~A}$ & TGTTCAGACCAGCATTACTGGC & GAGATCGCATTACGGACATTG & $95^{\circ} \mathrm{C}\left(3^{\prime}\right) \cdot\left[94\left(30^{\prime \prime}\right) \cdot 53^{\circ} \mathrm{C} \cdot\left(30^{\prime \prime}\right) .72^{\circ} \mathrm{C}\left(\mathrm{I}^{\prime}\right)\right] \times 30.72^{\circ} \mathrm{C} \cdot\left(3^{\prime}\right)$ \\
\hline EvxA & GGCCAACGTGCGTCGTTAT & ACGGCCACGTCTGCCGTTGT & $95^{\circ} \mathrm{C}\left(3^{\prime}\right) \cdot\left[94\left(30^{\prime \prime}\right) \cdot 55^{\circ} \mathrm{C} \cdot\left(30^{\prime \prime}\right) \cdot 72^{\circ} \mathrm{C}\left(\mathrm{I}^{\prime}\right)\right] \times 30.72^{\circ} \mathrm{C} \cdot\left(3^{\prime}\right)$ \\
\hline
\end{tabular}

ter polymorphism (detection of base changes), and c) $F_{1}$ inheritance (transmission probability). According to these criteria, SNPs in position 114, 158, 328 were selected for Hox5, and those in position 108, 161, 279 for Hox10 (Table 5).

\section{Culturing}

Fusaro/Castellamare di Stabia hybrids were cultured according to a published protocol [49], with modifications.

\section{Linkage disequilibrium and Genetic mapping}

SNP oligos used to perform the backcross analysis are described in Table 5. Sample reactions were prepared in $10 \mu \mathrm{l}$ containing $5 \mu \mathrm{l}$ of SNaPshot Multiplex Ready Reaction Mix (Applied Biosystems, Foster City, CA., USA), $3 \mu \mathrm{l}$ of PCR products, $1 \mu \mathrm{l}$ of specific primers, $1 \mu \mathrm{l}$ of deionized water. Thermal cycling was performed on a MJ DNA Engine PTC 200 at SBM, following standard procedure using an annealing temperature of $42^{\circ} \mathrm{C}$. Post-extension treatment was performed using the Applied Biosystems 3730 DNA Analyzer. Data were analyzed by eye with GeneMapper v.3.7 (Applied Biosystems).

The metric $\mathrm{D}$ is a quantitative measure of allelic association. Given the two sites 1 and 2, $x_{12}$ is the frequency of the corresponding haplotype and $p_{1}, q_{2}$ are the marginal allele frequencies. Hence, $\mathrm{D}=x_{12}-\left(p_{1}\right)\left(q_{2}\right)$ [50]. $\mathrm{D}^{\prime}$ is obtained by normalising $\mathrm{D}$ over the theoretical maximum $\mathrm{D}$, given the specific allele frequencies, such that $\mathrm{D}^{\prime}=\mathrm{D} / \mathrm{D}_{\max }[36]$ Finally, the correlation factor $\mathrm{r}^{2}$ is equal to $\mathrm{D}^{2} /\left(p_{1}\right)\left(q_{2}\right)$.

Table 5: SNP primers and Ful vs CdS polymorphic sites.

\begin{tabular}{lll}
\hline Primer & Sequence (5' to 3') & Fu vs CdS SNP \\
& & \\
\hline 5SNPII4 & (GACA) ${ }_{2}$ GATGTTTATGACGAAGAA & A - C \\
5 SNPI58 & GACACGAGTTGTTTGGGTAATGG & G - A \\
5SNP328 & CAGATATTGGACCAAAAGTTCC & T-A \\
IOSNPI08 & (GACA $)_{3}$ TTATAATATATCTCTTGT & A- T \\
IOSNPI6I & CAGATTTATTTTTGTGAATTA & G - A \\
IOSNP279 & GACACAAATACTTGATTAAGTA & A-G
\end{tabular}

Normalized linkage disequilibrium measure [D'] and the correlation coefficient $\left(\mathrm{r}^{2}\right)$ were calculated and visualized using HaploView v.3.32 [51] with a phased genotype matrix. Genetic distance (cM) between Hox-5 and -10 loci was calculated using MapMaker/EXP v.3.0 [52] with a threshold (LOD) greater than 3 and ordered with a LOD score of 1.44 [38]. The genetic distance was calculated using Haldane's mapping function [53].

\section{Authors' contributions}

LC (corresponding author) performed acquisition and analysis of data and drafted the manuscript; $\mathrm{MB}$ and $\mathrm{EB}$ developed the SNP detection procedure; NA gave a fundamental help in revisiting and improving the quality of the manuscript; PS is the PI who conceived and coordinated the project, and made important contributions to the text. All authors read and approved the final manuscript.

\section{Acknowledgements}

Authors wish to thank: J. Bishop (MBL, Plymouth) for providing $C$. intestinalis sp. B specimens, the Marine Resources for Research Service at SZN for culturing assistance; Francesco Esposito for providing live food for ascidians; C. Bowler and M. Idris for comments and suggestions. This research was supported by an OPEN University $\mathrm{PhD}$ programme and a grant from the European Union (EU) (Marine Genomics Europe, WP36 "The genetic identity of species").

\section{References}

I. Delsuc F, Brinkmann H, Chourrout D, Philippe H: Tunicates and not cephalochordates are the closest living relatives of vertebrates. Nature 2006, 439:965-968.

2. Kowalevsky A: Entwicklungegeschichte der einfachen Ascidien. Mem Acad St Petersbourg Ser 1866, 7:I-10.

3. Garstang W: The morphology of the Tunicata, and its bearings on the Phylogeny of the Chordata. Q J Microsc Sci 1928, 72:5I-187.

4. Satoh N: Developmental biology of ascidians. Cambridge Univesity Press, Cambridge; 1994.

5. Wada H, Satoh N: Details of the evolutionary history from invertebrate to vertebrate, as deduced from the sequences of I 8S rDNA. Proc Natl Acad Sci USA 1994, 9 I: | 80 I- 1804.

6. Moret F, Christiaen L, Deyts C, Blin M, Vernier P, Joly JS: Regulatory gene expressions in the ascidian ventral sensory vesicle: evolutionary relationships with the vertebrate hypothalamus. Dev Biol 2005, 277:567-579.

7. Jeffery WR, Strickler AG, Yamamoto Y: Migratory neural crestlike cells form body pigmentation in a Urochordate embryo. Nature 2004, 431:696-699. 
8. Caputi L, Andreakis N, Cirino P, Mastrototaro F, Sordino P: Cryptic speciation in a model invertebrate chordate. Proc Natl Acad Sci USA 2007, 29; 104(22):9364-9.

9. Iannelli F, Pesole G, Sordino P, Gissi C: Mitogenomics reveals two cryptic species in Ciona intestinalis. Trends Genet 2007, 23(9):419-22.

10. Suzuki MM, Nishikawa T, Bird A: Genomic approaches reveal unexpected genetic divergence within Ciona intestinalis. J Mol Evol 2005, 61:627-635.

II. Nydam ML, Harrison RG: Genealogical relationships within and among shallow-water Ciona species (Ascidiacea). Mar Biol 2007, I5 I(5): | $839-1874$.

12. Katz MJ: Comparative anatomy of the tunicate tadpole, Ciona intestinalis. Biol Bull 1983, 164: I-27.

13. Chiba S, Sasaki A, Nakayama A, Takamura K, Satoh N: Development of the Ciona intestinalis juveniles (through $2^{\text {nd }}$ ascidian stage). Zool Sci 2004, 2 I:285-298.

14. Dehal P, Satou Y, Campbell RK, Chapman J, Degnan B, De Tomaso A, Davidson B, Di Gregorio A, Gelpke M, Goodstein DM, Harafuji N, Hastings KE, Ho I, Hotta K, Huang W, Kawashima T, Lemaire P, Martinez D, Meinertzhagen IA, Necula S, Nonaka M, Putnam N, Rash S, Saiga H, Satake M, Terry A, Yamada L, Wang HG, Awazu S, Azumi K, Boore J, Branno M, Chin-Bow S, DeSantis R, Doyle S, Francino P, Keys DN, Haga S, Hayashi H, Hino K, Imai KS, Inaba K, Kano S, Kobayashi K, Kobayashi M, Lee BI, Makabe KW, Manohar C, Matassi G, Medina M, Mochizuki Y, Mount S, Morishita T, Miura S, Nakayama A Nishizaka S, Nomoto H, Ohta F, Oishi K, Rigoutsos I, Sano M, Sasaki A, Sasakura Y, Shoguchi E, Shin-i T, Spagnuolo A, Stainier D, Suzuki MM, Tassy O, Takatori N, Tokuoka M, Yagi K, Yoshizaki F, Wada S, Zhang C, Hyatt PD, Larimer F, Detter C, Doggett N, Glavina T, Hawkins T, Richardson P, Lucas S, Kohara Y, Levine M, Satoh N, Rokhsar DS: The draft genome of Ciona intestinalis: insights into chordate and vertebrate origins. Science 2002, 298:2157-2167.

15. Small KS, Brudno M, Hill MM, Sidow A: Extreme genomic variation in a natural population. Proc Natl Acad Sci USA 2007 I 04(13):5698-703.

16. Brookes AJ: The essence of SNPs. Gene 1999, 234:177-186.

17. Wang DG, Fan JB, Siao CJ, Berno A, Young P, Sapolsky R, Ghandour G, Perkins N, Winchester E, Spencer J, Kruglyak L, Stein L, Hsie L Topaloglou T, Hubbell E, Robinson E, Mittmann M, Morris MS, Shen N, Kilburn D, Rioux J, Nusbaum C, Rozen S, Hudson T], Lipshutz R, Chee M, Lander ES: Large-scale identification, mapping, and genotyping of single-nucleotide polymorphisms in the human genome. Science 1998, 280(5366): 1077-1082.

18. Morlais I, Severson DW: Intraspecific DNA variation in nuclear genes of the mosquito Aedes aegypti. Insect Mol Biol 2003, 1 2(6):63|-639.

19. Brumfield RT, Beerli P, Nickerson DA, Edwards SV: Single nucleotide polymorphisms (SNPs) as markers in phylogeography. Trends Ecol Evol 2003, 18:249-256.

20. Steffens M, Lamina C, Illig T, Bettecken T, Vogler R, Entz P, Suk E-K, Toliat MR, Klopp N, Caliebe A, König IR, Köhler K, Lüdemann J, Diaz Lacava A, Fimmers R, Lichtner P, Ziegler A, Wolf A, Krawczak M, Nürnberg $P$, Hampe J, Schreiber S, Meitinger T, Wichmann H-E, Roeder K, Wienker TF, Baur MP: SNP-Based Analysis of Genetic Substructure in the German Population. Hum Hered 2006, 62(I):20-9.

21. Boffelli D, Weer CV, Weng L, Lewis KD, Shoukry MI, Pachter L, Keys DN, Rubin EM: Intraspecies sequence comparisons for annotating genomes. Genome Res 2004, I 4( I 2):2406-II.

22. Seo HC, Edvardsen RB, Maeland AD, Bjordal M, Jensen MF, Hansen $A$, Flaat M, Weissenbach J, Lehrach $H$, Wincker $P$, Reinhardt $R$, Chourrout D: Hox cluster disintegration with persistent anteroposterior order of expression in Oikopleura dioica. Nature 2004, 43 I:67-7I.

23. Ikuta T, Yoshida N, Satoh N, Saiga H: Ciona intestinalis Hox gene cluster: Its dispersed structure and residual colinear expression in development. Proc Natl Acad Sci USA 2004, 101:15118-15123.

24. Cameron RA, Rowen L, Nesbitt R, Bloom S, Rast JP, Berney K, Arenas-Mena C, Martinez P, Lucas S, Richardson PM, Davidson EH, Peterson $\mathrm{KJ}$, Hood L: Unusual gene order and organization of the sea urchin hox cluster. J Exp Zoolog B Mol Dev Evol 2006, I 5,306(I):45-58.
25. Palumbi SR, Baker CS: Contrasting population structure from nuclear intron sequences and mtDNA of humpback whales. Mol Biol Evol 1994, I I:426-435.

26. Moriyama EN, Powell JR: Intraspecific nuclear DNA variation in Drosophila. Mol Biol Evol 1996, I3(1):26I-277.

27. Wondji CS, Hemingway J, Ranson $\mathrm{H}$ : Identification and analysis of single nucleotide polymorphisms (SNPs) in the mosquito Anopheles funestus, malaria vector. BMC Genomics 2007, 8:5

28. Shoguchi E, Kawashima T, Nishida-Umehara C, Matsuda Y, Satoh N: Molecular cytogenetic characterization of Ciona intestinalis chromosomes. Zoolog Sci 2005, 22(5):5 I I-6.

29. Hughes AL, Nei M: Pattern of nucleotide substitution at major histocompatibility complex class I loci reveals overdominant selection. Nature 1988, 8;335(6186):167-70.

30. Messier W, Stewart CB: Episodic adaptive evolution of primate lysozymes. Nature 1997, 385:15I-154.

31. Wheat CW, Watt WB, Pollock DD, Schulte PM: From DNA to fitness differences: sequences and structures of adaptive variants of Colias phosphoglucose isomerase (PGI). Mol Biol Evol 2006, 23(3):499-5I2.

32. Holliday R, Grigg GW: DNA methylation and mutation. Mutat Res 1993, 285(I):6I-67.

33. Hughes AL, Nei M: Pattern of nucleotide substitution at major histocompatibility complex class I loci reveals overdominant selection. Nature 1988, 8,335(6186): |67-70.

34. Guindon S, Rodrigo AG, Dyer KA, Huelsenbeck JP: Modeling the site-specific variation of selection patterns along lineages. Proc Natl Acad Sci U S A 2004, I 0 I (35): | 2957-62.

35. Lynch VJ, Roth JJ, Wagner GP: Adaptive evolution of Hox-gene homeodomains after cluster duplications. BMC Evolutionary Biology 2006, 6:86. doi:I0.1/86/I47|-2|48-6-86

36. Lewontin RC: The Interaction of Selection and Linkage. I. General Considerations; Heterotic Models. Genetics 1964, 49(I):49-67.

37. Hill WG, Robertson A: Linkage disequilibrium in finite populations. Theor Appl Genet 1968, 38:226-23 I.

38. Kano S, Satoh N, Sordino P: Primary genetic linkage map of the ascidian, Ciona intestinalis. Zoolog Sci 2006, 23(I):3I-39.

39. De Tomaso AW, Weissman IL: Initial characterization of a protochordate histocompatibility locus. Immunogenetics 2003, 55:480-490

40. Khalturin K, Kurn U, Pinnow N, Bosch TGC: Towards a molecular code for individuality in the absence of MHC: screening for individually variable genes in the urochordate Ciona intestinalis. Dev Comp Immunol 2005, 29(9):759-73.

41. Satou Y, Kawashima T, Shoguchi E, Nakayama A, Satoh N: An integrated database of the ascidian, Ciona intestinalis: towards functional genomics. Zoolog Sci 2005, 22(8):837-43.

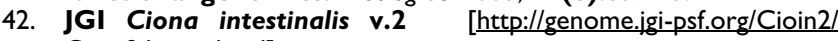
Cioin2.home.html]

43. Ghost database [http://ghost.zool.kyoto-u.ac.jp/indexrl.html]

44. Thompson JD, Higgins DG, Gibson TJ: CLUSTAL W: improving the sensitivity of progressive multiple sequence alignment through sequence weighting, position-specific gap penalties and weight matrix choice. Nucleic Acids Res 1994, 22(22):4673-4680

45. Hall TA: BioEdit: a user-friendly biological sequence alignment editor and analysis program for Windows 95/98/NT. Nucleic Acids Symp Ser 1999, 41:95-98.

46. Xia X, Xie Z: DAMBE: software package for data analysis in molecular biology and evolution. J Hered 200I, 92(4):37I-3.

47. Rozas J, Sanchez-DelBarrio JC, Messeguer X, Rozas R: DnaSP, DNA polymorphism analyses by the coalescent and other methods. Bioinformatics 2003, I (1 (8):2496-2497.

48. Kumar S, Tamura K, Nei M: MEGA3: Integrated software for Molecular Evolutionary Genetics Analysis and sequence alignment. Briefings in Bioinformatics 2004, 5:150-163.

49. Cirino P, Toscano A, Caramiello D, Macina A, Miraglia V, Monte A: Laboratory culture of the ascidian Ciona intestinalis (L.): a model system for molecular developmental biology research. Mar Mod Elec Rec 2002 [http://www.mbl.edu/Biological Bulletin/MMER/cirino/CirCon.html]. serial online

50. Lewontin RC, Kojima K: The evolutionary dynamics of complex polymorphisms. Evolution 1960, 14:458-472. 
5I. Barrett JC, Fry B, Maller J, Daly MJ: Haploview: analysis and visualization of LD and haplotype maps. Bioinformatics 2005, 21:263-265.

52. Lincoln S, Daly M, Lander E: Constructing genetic maps with MAPMAKER/EXP 3.0. In Whitehead Technical Report 3rd edition. Boston: Whitehead Institute; 1992.

53. Haldane JBS: The combination of linkage values and the calculation of distance between loci of linked factors. J Genet 1919 , 8:299-309.

Publish with Biomed Central and every scientist can read your work free of charge

"BioMed Central will be the most significant development for disseminating the results of biomedical research in our lifetime. " Sir Paul Nurse, Cancer Research UK

Your research papers will be:

- available free of charge to the entire biomedical community

- peer reviewed and published immediately upon acceptance

- cited in PubMed and archived on PubMed Central

- yours - you keep the copyright

Submit your manuscript here:

http://www.biomedcentral.com/info/publishing_adv.asp
BioMedcentral 